\title{
Challenges and perspectives for immunotherapy in oesophageal cancer: A look to the future (Review)
}

\author{
ANDREA LAMPIS ${ }^{1,2}$, MARGHERITA RATTI ${ }^{1-3}$, MICHELE GHIDINI ${ }^{4}$, MILKO B. MIRCHEV $^{5}$, \\ ALI FUAT OKUDUCU ${ }^{6}$, NICOLA VALERI ${ }^{1,2,7}$ and JENS CLAUS HAHNE ${ }^{1,2}$ \\ ${ }^{1}$ Division of Molecular Pathology, ${ }^{2}$ Centre for Evolution and Cancer, The Institute of Cancer Research, \\ Sutton SM25NG, UK; ${ }^{3}$ Medical Department, Division of Oncology, Hospital Trust of Cremona, I-26100 Cremona; \\ ${ }^{4}$ Division of Medical Oncology, Hospital Policlinic 'Fondazione IRCCS Ca' Granda Ospedale Maggiore', \\ I-20122 Milan, Italy; ${ }^{5}$ Clinic of Gastroenterology, Medical University, 9002 Varna, Bulgaria; ${ }^{6}$ Pathology Länggasse, \\ 3063 Bern, Switzerland; ${ }^{7}$ Department of Medicine, The Royal Marsden NHS Foundation Trust, Sutton SM25NG, UK
}

Received December 21, 2020; Accepted February 25, 2021

DOI: $10.3892 / \mathrm{ijmm} .2021 .4930$

\begin{abstract}
Oesophageal cancer is one of the most aggressive malignancies with limited treatment options, thus resulting in a high morbidity and mortality. With 5-year survival rates of only $5-10 \%$, oesophageal cancer holds a dismal prognosis for patients. In order to improve overall survival, the early diagnosis and tools for patient stratification for personalized treatment are urgent needs. A minority of oesophageal cancers belong to the spectrum of Lynch syndrome-associated cancers and are characterized by microsatellite instability (MSI). Microsatellite instability is a consequence of defective mismatch repair protein functions and it has
\end{abstract}

Correspondence to: Dr Jens Claus Hahne, Division of Molecular Pathology, The Institute of Cancer Research, 15 Cotswold Road, Sutton SM25NG, UK

E-mail: jens.hanhe@icr.ac.uk

Abbreviations: B7-H1, B7-homolg1; CAR, chimeric antigen receptor; $\mathrm{CCL}$, chemokine (C-C motif) ligand; $\mathrm{CD}$, cluster of differentiation; CTLA-4, cytotoxic $\mathrm{T}$ lymphocyte-associated antigen-4 (CD152); FDA, US Food and Drug Administration; HER-2, human epidermal growth factor receptor-2; HLA, human leukocyte antigen; ICOS, inducible T-cell costimulatory molecule; IDO-1, indoleamine-2,3-dioxygenase-1; IFN, interferon; IL-18, interleukin-18; MAGE, melanoma antigen gene; MDSC, myeloid-derived suppressor cell; MHC major histocompatibility complex; MICA, MHC class I chain-related protein A; MICB, MHC class I chain-related protein B; MSI, microsatellite instability; NK, cells natural killer cells; NY-ESO-1, New York oesophageal squamous cell carcinoma-1 protein; PD-1 programmed cell death protein 1 (CD279); PD-L1, programmed cell death 1 ligand 1 (CD274); RNA, ribonucleic acid; TCR, T-cell receptor; TREGs, regulatory $\mathrm{T}$-cells

Key words: immunotherapy, oesophageal cancer, immune checkpoint inhibitors, adoptive T-cell therapy, peptide vaccine, oncolytic viruses been well characterized in other gastrointestinal tumours, such as colorectal and gastric cancer. In the latter, high levels of MSI are associated with a better prognosis and with an increased benefit to immune-based therapies. Therefore, similar therapeutic approaches could offer an opportunity of treatment for oesophageal cancer patients with MSI. Apart from immune checkpoint inhibitors, other immunotherapies such as adoptive T-cell transfer, peptide vaccine and oncolytic viruses are under investigation in oesophageal cancer patients. In the present review, the rationale and current knowledge about immunotherapies in oesophageal cancer are summarised.

\section{Contents}

1. Introduction

2. Biological background of tumour immunotherapy

3. Immunotherapy in oesophageal cancer

4. Immune checkpoint inhibitors

5. Adoptive T-cell therapy

6. Peptide vaccine

7. Oncolytic viruses

8. Conclusion and perspectives

\section{Introduction}

The incidence of oesophageal cancer has rapidly increased over the past years and it is currently the fifth most common type of cancer worldwide with a very high mortality rate $(1,2)$. Oesophageal cancer is subdivided into two groups according to its histological appearance: Oesophageal squamous cell carcinoma (predominant in western countries) and oesophageal adenocarcinoma (most common form in Asia) $(3,4)$. Thus far, no molecular markers for prognosis or treatment efficacy have been discovered for squamous cell carcinoma. For oesophageal adenocarcinoma, the human epidermal growth factor receptor-2 (HER-2) status has been proven to be an efficient biomarker. HER-2 is scored by 
immunohistochemistry for protein expression or fluorescent in situ hybridization for HER2 gene amplification (5). If positive, a targeted therapy option with trastuzumab for HER-2 is the treatment of choice $(6,7)$. Nevertheless, oesophageal cancer is mostly treated by radiation in combination with chemotherapy or surgery. However, the 5-year overall survival rate remains very poor and is only at $5-10 \%(8,9)$. Nonetheless, surgery is not applicable in approximately half of patients as distant metastases are already present at the time of diagnosis (10). The most commonly used chemotherapeutic agents for oesophageal cancer treatment are 5'-fluorouracil and platinum agents in combination with radiotherapy $(11,12)$.

The major risk factors for oesophageal cancer are represented by smoking, the consumption of hot tea, red meat consumption, poor oral health, low intake of fresh fruits and vegetables, alcohol abuse, obesity, nass use (a chewing tobacco product), opium consumption and low socioeconomic status (13-24). The majority of these risk factors induce gene mutations which can be recognized by the immune system (25). In addition, a minority of oesophageal cancers belong to the spectrum of Lynch syndrome-associated cancers and are characterized by microsatellite instability (MSI) (26). Therefore, the use of immunotherapy approaches in oesophageal cancer appears to be an attractive novel therapeutic strategy.

The identified main reasons for the high mortality rate of patients with oesophageal cancer are mainly the late stage of diagnosis (13) and the key role of tumour microenvironment in this type of cancer (27), where the surrounding stromal cells seem to exert an important influence in supporting tumour cell survival (27). Apart from cancer-associated fibroblasts, that are able to support tumour growth and metastasis by altering the extracellular matrix by secreting growth factors and cytokines, several immune cells [e.g., myeloid-derived suppressor cells, tumour-associated macrophages and regulatory T-cells (TREGS)] are involved in support the development of oesophageal cancer (27). Therapies targeting the tumour microenvironment and/or the immune system may thus be able to increase the survival of patients with oesophageal cancer. Over the past years, immunotherapy in particular has revolutionized the management and outcome of several types of cancer, such as melanoma, lung, gastric and kidney cancer (28). Therefore, it may be advantageous to explore the benefits from immunotherapy for oesophageal cancer. The identification and selection of robust biomarkers predicting clinical benefit are also mandatory before commencing immunotherapy treatment, as even though generally well-tolerated compared to standard therapies, immunotherapy is associated occasionally with severe toxic side-effects, such as cutaneous, gastrointestinal, endocrine and hepatic toxicity. Thus, only patients with oesophageal cancer who have the highest likelihood of benefit from immunotherapy should be offered this therapeutic regimen. For example, it is well-established that immune checkpoint inhibitors are particularly effective against mismatch repair-deficient tumours (29). In general, tumours with MSI have a higher mutation rate, which increases the probability for the immune system to recognize tumour cells (29-31). Recently, several reviews have summarized the current knowledge on immunotherapy and cancer (32-34). The present review focuses on the current state of the use of immunotherapy in oesophageal cancer.

\section{Biological background of tumour immunotherapy}

The immune system is a highly complex and specialised biological network including specific cells, protein and organs and is usually composed of two types: Adaptive (specific) and innate (non-specific) (35). In recognising and preventing the spread of cancer cells, the innate immunity components, such as natural killer (NK) cells, dendritic cells and macrophages are of pivotal importance; nevertheless, T-cells from the adaptive immune are recruited in order to track and kill tumour cells $(35,36)$. Recently, a new model that provides a mechanistic explanation of this interaction termed 'cancer-immunity cycle' has been suggested (35). According to this model, dead cancer cells release antigens that in turn are recognised by antigen-presenting cells (particularly by dendritic cells). This results in the priming and activation of dendritic cells and T-cells in lymph nodes, followed by the recruitment of helper T-cells [cluster of differentiation (CD) $4^{+}-\mathrm{T}$-cells] and cytotoxic T-lymphocytes (CD8+-T-cells) at the tumour site. Following the infiltration of the tumour microenvironment, immune cells recognize and attack tumour cells that results in the release of further tumour antigens. The whole cancer-immunity cycle is fine-tuned by different stimulating and inhibitory factors, such as chemokines, cytokines, metabolic compounds, surface proteins and immune checkpoint receptors to prevent autoimmunity (37).

Cancer cells use different strategies to escape the immune system, and to capture and reprogram immune cells, leading to immune evasion. Among these strategies is the mechanisms of shedding of MHC class I chain-related protein A and B (MICA and MICB) from tumour cells into the tumour microenvironment as protection against NK cell-mediated killing (38-40). In addition, tumour cells express immune checkpoint proteins, such as programmed cell death 1 ligand 1 (PD-L1) and receptors, such as cytotoxic $\mathrm{T}$ lymphocyte-associated antigen-4 (CTLA-4) on the surface, but also secrete exosomes which contains these immune checkpoint regulators. After binding to proteins expressed on the immune cells (T-cells, B-cells and myeloid cells) the checkpoint regulators exert an inhibitory signal and lead to the suppression of the immune response (41-43).

Furthermore, cancer cells, as well as tumour-associated macrophages are able to secrete chemokines, such as chemokine (C-C motif) ligand (CCL)-17 and CCl-22 which attract a subpopulation of T-cells, the so-called TREGs. TREGs are known to regulate and suppress the activity of other immune cells and to help preventing autoimmune reactions under healthy conditions $(44,45)$. In tumour tissue, TREGs protect cancer cells and foster tumour growth $(46,47)$. Moreover, CD8 ${ }^{+}$-T-cells are inhibited directly by myeloid-derived suppressor cells (MDSCs) which are stimulated by tumour-derived growth factors $(48,49)$. In addition, stromal cells in the tumour microenvironment inhibit the function of the immune system further supporting tumour progression and metastasis (50). 


\section{Immunotherapy in oesophageal cancer}

The immune system is a complex network of interacting cells and biochemical signals that orchestrate the recognition and attack of external antigens, whilst preventing autoimmune reactions. Under physiological conditions, this is guaranteed by a fine-tuned interplay between immune cells and a balance between stimulatory and inhibitory signals $(51,52)$. Cancer cells often find a way to de-regulate the balanced immune system by manipulating signalling pathways to evade from immune surveillance. To overcome the mechanisms of tumour immune evasion and use the immune system as weapon against cancer, either agonists of stimulatory receptors or antagonists of inhibitory signals can be used (41). Nevertheless, according to currently available study results, only a subset of oesophageal cancer patients may benefit from immunotherapy (53). Therefore, there is an urgent need to identify biomarkers for the prediction of the benefit from immunotherapy, so that patients can be selected for treatment and those who have no benefit from immunotherapy are spared from side-effects (e.g., cutaneous, gastrointestinal, endocrine and hepatic toxicity) and therapy failure. In light of this scenario, currently, several clinical trials are underway to evaluate the efficacy of different immunotherapies combined with other treatment options in oesophageal cancer patients (Table I) with the aim to increase the therapeutic option for oesophageal cancer patients. The majority of these studies are ongoing Phase 2 studies and the results have not been published yet.

In the following section, the main immunotherapy approaches that have been studied thus far will be discussed (Fig. 1).

\section{Immune checkpoint inhibitors}

Immune checkpoints are of pivotal importance to prevent autoimmunity reactions by the inhibition of antigen recognition via T-cell receptors (TCRs) $(41,54,55)$. Cancer cells use immune checkpoint proteins to inactivate the adaptive immune system by blocking tumour specific T-cells and escape from immune surveillance. Thus far, the immune checkpoint receptors programmed cell death protein 1 (PD-1; also known as CD279) and CTLA-4 (also known as CD152) have been found to be associated with the inhibition and downregulation of T-cell activity $(41,54,55)$.

PD-1 receptor is highly expressed on T-cells, B-cells and NK cells. The ligand for PD-1 receptor is PD-L1 often also termed B7-homolog 1 (B7-H1) or CD274. This molecule is expressed in peripheral tissues following exposure to inflammatory cytokines and limits T-cell activity (56). Furthermore, interleukin (IL)-18, an inflammatory cytokine that accumulates in the tumour microenvironment, results in the upregulation of PD-L1 in activated mature NK cells and triggers immunosuppression (57). In melanoma, lung, breast, pancreatic, gastric, colon, ovarian and oesophageal cancers, PD-L1 is often found overexpressed on cancer cells (58). This enables tumour cells to interact with PD-1 receptors on T-cells and this interaction prevents T-cell activation, proliferation and ultimately leading to T-cell apoptosis (41).

The expression of CTLA-4 receptor is restricted to activated T-cells (e.g., TREGs), whereas the homolog CD28 is also expressed on non-activated T-cells. Ligands for both receptors are the immunoglobulin proteins B7-1 (CD80) and B7-2 (CD86), which are expressed early during the immune response on antigen-presenting cells, such as macrophages and dendritic cells or on B-cells and monocytes, respectively. CTLA-4 receptor has a higher affinity for ligands and competing with $\mathrm{CD} 28$ on ligand binding; the interaction between $\mathrm{B} 7-1$ or B7-2 with $\mathrm{CD} 28$ results in T-cell activation, whereas the interaction with CTLA-4 inhibits T-cell activation at an early stage $(59,60)$.

It has been widely proven that PD-L1 expression is one of the key mechanisms through which several cancers evade the immune response; thus, it is not surprising that inhibitors of PD-L1 and PD-1 have been identified thus far as one of most efficient and broadly used immunotherapies for cancer (61-71). Recently, a monoclonal antibody targeting PD-1, pembrolizumab, has been approved for the treatment of oesophageal and oesophago-gastric junction adenocarcinoma by the US Food and Drug Administration (FDA) (8). The prerequisite for the treatment of oesophageal cancer with pembrolizumab is either a proven PD-L1 expression on the cancer cells and a high MSI, or a proven defective mismatch repair system. Therefore, most probably, the subgroup of Lynch syndrome-associated oesophageal cancers patients may benefit from this new treatment option. According to a previous study, it is possible to predict the efficacy of pembrolizumab in patients with oesophageal cancer by using a six-gene interferon- $\gamma$ gene expression signature (72). This offers the possibility to stratify oesophageal cancer patients and limit the targeted treatment to the group that will most probably benefit from the anti-PD-L1 therapy.

Earlier in 2020, the FDA approved nivolumab, a fully human monoclonal antibody against PD-1 (73) for patients with unresectable advanced, recurrent or metastatic oesophageal squamous cell carcinoma as a second line following 5 '-fluorouracil- and platinum-based chemotherapy. The overall survival benefit is 2.5 months according to a phase 3 clinical study (74).

Currently, combination therapies with anti-PD1 and anti-CTLA-4 antibodies are forthcoming (75). According to the first preliminary results from clinical studies (NCT02743494, CheckMate 648 and CheckMate 649) the combination of nivolumab with the anti CDLA-4 antibody, ipilimumab, led to an improved clinical response in oesophageal cancer compared to treatment with nivolumab alone $(76,77)$. The combination of nivolumab and ipilimumab appears to be safe; nevertheless, it must be considered that CTLA-4 blockade results in more severe and more common side-effects than it is the case for targeting PD-1/PD-L1 alone. Therefore, the development of novel strategies for reducing serious adverse side-effects is an urgent need and the first steps need to be carefully controlled (78).

As a potential biomarker for prediction of the response to immune checkpoint inhibitor therapy, the total amount of PD-1 ${ }^{+}$ $\mathrm{CD} 4^{+} \mathrm{T}$-cells in the tumour microenvironment is discussed. According to the presence or absence of $\mathrm{CD} 4^{+} \mathrm{T}$-cells and PD-1 expression in the tumour microenvironment, a stratification of patients is possible. The absence of $\mathrm{CD}^{+}{ }^{+} \mathrm{T}$-cells and PD-1 expression results in immunological ignorance; in a situation where only one component (either $\mathrm{CD} 4^{+} \mathrm{T}$-cells or PD-1) 
Table I. Clinical trials investigating immunotherapeutic options in combination with other therapeutic options in oesophageal cancer patients.

\begin{tabular}{|c|c|c|c|c|c|}
\hline $\begin{array}{l}\text { Immuno- } \\
\text { therapeutic } \\
\text { option }\end{array}$ & $\begin{array}{c}\text { Stage of } \\
\text { development }\end{array}$ & Combined with & $\begin{array}{l}\text { ClinicalTrials } \\
\text { gov.identifier }\end{array}$ & $\begin{array}{l}\text { Start } \\
\text { time }\end{array}$ & Current status \\
\hline
\end{tabular}

Immune checkpoint inhibitor treatment

\begin{tabular}{|c|c|c|c|c|c|}
\hline \multirow[t]{16}{*}{ Nivolumab } & Phase $1 / 2$ & Chemoradiotherapy & NCT03278626 & 2017 & Active, but not recruiting \\
\hline & Phase $1 / 2$ & Chemoradiotherapy & NCT03544736 & 2018 & Recruiting \\
\hline & Phase 2 & $\begin{array}{l}\text { Chemoradiotherapy + } \\
\text { Ipilimumab }\end{array}$ & NCT03604991 & 2018 & Recruiting \\
\hline & Phase 2 & $\begin{array}{l}\text { Chemoradiotherapy + } \\
\text { Ipilimumab }\end{array}$ & NCT03437200 & 2018 & Recruiting \\
\hline & Phase 3 & $\begin{array}{l}\text { Ipilimumab + } \\
\text { Chemotherapy }\end{array}$ & NCT3143153 & 2017 & Recruiting \\
\hline & Phase 2 & Ipilimumab & NCT03416244 & 2018 & Recruiting \\
\hline & Phase $1 / 2$ & $\begin{array}{l}\text { Ipilimumab + } \\
\text { INCAGN01949 }\end{array}$ & NCT03241173 & 2017 & $\begin{array}{l}\text { Completed in } 2020 \text {, but no } \\
\text { results published }\end{array}$ \\
\hline & Phase 1 & $\begin{array}{l}\text { Chemoradiotherapy + } \\
\text { Relatlimab }\end{array}$ & NCT03044613 & 2017 & Recruiting \\
\hline & Phase 2 & $\begin{array}{l}\text { Chemoradiotherapy + } \\
\text { Cetuximab }\end{array}$ & NCT04229459 & 2020 & Recruiting \\
\hline & Phase 1 & Chemotherapy & NCT03914443 & 2019 & Recruiting \\
\hline & Phase 3 & After chemotherapy & NCT02569242 & 2015 & Active, but not recruiting \\
\hline & Phase 3 & $\begin{array}{l}\text { After chemoradiotherapy } \\
\text { and surgery }\end{array}$ & NCT02743494 & 2016 & Active but not recruiting \\
\hline & Phase 1 & + Rucaparib & NCT03995017 & 2019 & Recruiting \\
\hline & Phase 1 & + Mogamulizumab & NCT02946671 & 2016 & $\begin{array}{l}\text { Completed in } 2020 \text {, but no } \\
\text { results published }\end{array}$ \\
\hline & Phase 1 & + Mogamulizumab & NCT02476123 & 2015 & $\begin{array}{l}\text { Completed in } 2020 \text {, but no } \\
\text { results published }\end{array}$ \\
\hline & Phase $1 / 2$ & Radiotherapy & NCT03544736 & 2018 & Recruiting \\
\hline \multirow[t]{16}{*}{ Pembrolizumab } & Phase 2 & Chemoradiotherapy & NCT02844075 & 2016 & Active, but not recruiting \\
\hline & Phase 2 & Chemoradiotherapy & NCT03064490 & 2017 & Recruiting \\
\hline & Phase 2 & Chemoradiotherapy & NCT03322267 & 2017 & Recruiting \\
\hline & Phase 1 & Chemoradiotherapy & NCT03792347 & 2019 & Active, but not recruiting \\
\hline & Phase 2 & $\begin{array}{l}\text { Chemoradiotherapy + } \\
\text { chemotherapy }\end{array}$ & NCT02998268 & 2016 & Active, but not recruiting \\
\hline & Phase 2 & $\begin{array}{l}\text { After chemoradiotherapy } \\
\text { and surgery }\end{array}$ & NCT02844075 & 2016 & Active but not recruiting \\
\hline & Phase 2 & $\begin{array}{l}\text { After } \\
\text { chemoradiotherapy and } \\
\text { surgery }\end{array}$ & NCT03322267 & 2017 & Recruiting \\
\hline & Phase 2 & Chemotherapy + Trastuzumab & NCT02954536 & 2016 & Recruiting \\
\hline & Phase 2 & + Epacadostat & NCT03592407 & 2018 & Withdrawn due to safety concerns \\
\hline & Phase 3 & Chemotherapy & NCT03189719 & 2017 & Active, but not recruiting \\
\hline & Phase 3 & Chemotherapy & NCT03881111 & 2019 & $\begin{array}{l}\text { Withdrawn due to protocol } \\
\text { amendment }\end{array}$ \\
\hline & Phase 2 & Chemotherapy & NCT04437212 & 2020 & Recruiting \\
\hline & Phase 2 & Radiotherapy & NCT02830594 & 2016 & Active, but not recruiting \\
\hline & Phase 1 & Brachytherapy: $16 \mathrm{~Gy} / 2 \mathrm{~F}$ & NCT02642809 & 2015 & Active, but not recruiting \\
\hline & Phase 1 & DKN-01 & NCT02013154 & 2013 & Active, but not recruiting \\
\hline & Phase $1 / 2$ & $\begin{array}{l}\text { INCAGN01876 + } \\
\text { Epacadostat }\end{array}$ & NCT03277352 & 2017 & $\begin{array}{l}\text { Completed in } 2020 \text {, but no } \\
\text { results published }\end{array}$ \\
\hline
\end{tabular}


Table I. Continued.

\begin{tabular}{lllll}
\hline $\begin{array}{l}\text { Immuno- } \\
\text { therapeutic } \\
\text { option }\end{array}$ & $\begin{array}{c}\text { Stage of } \\
\text { development }\end{array}$ & Combined with & $\begin{array}{l}\text { ClinicalTrials } \\
\text { govidentifier }\end{array}$ & $\begin{array}{l}\text { Start } \\
\text { time }\end{array}$
\end{tabular}

Immune checkpoint inhibitor treatment

\begin{tabular}{|c|c|c|c|c|c|}
\hline & Phase 2 & Tadalafil & NCT03993353 & 2019 & Recruiting \\
\hline & Phase 2 & + CRS-207 & NCT03122548 & 2019 & $\begin{array}{l}\text { Terminated because of low } \\
\text { enrolment and lack of clinical } \\
\text { activity in other CRS- } 207 \text { studies }\end{array}$ \\
\hline \multirow[t]{13}{*}{ Camrelizumab } & Phase 2 & Radiotherapy & NCT03200691 & 2017 & Recruiting \\
\hline & Phase 2 & Radiotherapy & NCT03187314 & 2017 & Recruiting \\
\hline & Phase 2 & Chemotherapy & NCT03917966 & 2019 & Not yet recruiting \\
\hline & Phase 3 & Chemotherapy & NCT03691090 & 2018 & Recruiting \\
\hline & Phase 2 & Chemoradiotherapy & NCT04390945 & 2020 & Recruiting \\
\hline & Phase 3 & Chemoradiotherapy & NCT04426955 & 2020 & Recruiting \\
\hline & Phase 3 & Chemoradiotherapy & NCT04404491 & 2020 & Recruiting \\
\hline & Phase 2 & After chemoradiotherapy & NCT03817658 & 2019 & Not yet recruiting \\
\hline & Phase 1 & After chemoradiotherapy & NCT03985046 & 2019 & Recruiting \\
\hline & Phase 2 & After chemoradiotherapy & NCT04286958 & 2020 & Recruiting \\
\hline & Phase 2 & Apatinib & NCT03736863 & 2019 & Not yet recruiting \\
\hline & Phase 2 & Apatinib + chemotherapy & NCT03603756 & 2018 & Recruiting \\
\hline & Phase 2 & Nimotuzumab & NCT03766178 & 2018 & Recruiting \\
\hline \multirow[t]{3}{*}{ Sintilimab } & Phase $1 / 2$ & Chemotherapy & NCT03946969 & 2019 & Recruiting \\
\hline & Phase 3 & Chemotherapy & NCT03748134 & 2018 & Recruiting \\
\hline & Phase 1 & Chemoradiotherapy & NCT03940001 & 2019 & Recruiting \\
\hline \multirow[t]{5}{*}{ Spartalizumab } & Phase 1 & LGK974 & NCT01351103 & 2011 & Recruiting \\
\hline & Phase $1 / 2$ & LAG525 & NCT02460224 & 2015 & Active, but not recruiting \\
\hline & Phase 2 & LAG525 & NCT03365791 & 2017 & Active, but not recruiting \\
\hline & Phase 2 & MCS110 & NCT03785496 & 2018 & Active, but not recruiting \\
\hline & Phase 1 & TNO155 & NCT04000529 & 2019 & Recruiting \\
\hline \multirow[t]{3}{*}{ Tislelizumab } & Phase 2 & Chemotherapy & NCT03469557 & 2018 & Active, but not recruiting \\
\hline & Phase 3 & Chemotherapy & NCT03783442 & 2018 & Recruiting \\
\hline & Phase 3 & Chemoradiotherapy & NCT03957590 & 2019 & Recruiting \\
\hline \multirow[t]{7}{*}{ Toripalimab } & Phase 2 & Chemotherapy & NCT03985670 & 2019 & Recruiting \\
\hline & Phase 3 & Chemotherapy & NCT03829969 & 2019 & Recruiting \\
\hline & Phase 2 & Chemoradiotherapy & NCT04006041 & 2019 & Recruiting \\
\hline & Phase 2 & Chemoradiotherapy & NCT04005170 & 2019 & Recruiting \\
\hline & Phase 2 & Chemoradiotherapy & NCT04084158 & 2019 & Recruiting \\
\hline & Phase 2 & Chemoradiotherapy & NCT04177875 & 2019 & Recruiting \\
\hline & Phase 2 & $\begin{array}{l}\text { After Chemoradiotherapy } \\
+ \text { surgery }\end{array}$ & NCT04437212 & 2020 & Recruiting \\
\hline HLX-10 & Phase 3 & Chemotherapy & NCT03958890 & 2019 & Recruiting \\
\hline \multirow[t]{3}{*}{ Avelumab } & Phase $1 / 2$ & Chemoradiotherapy & NCT03490292 & 2018 & Recruiting \\
\hline & Phase 2 & Chemoradiotherapy & NCT03800953 & 2019 & Not yet recruiting \\
\hline & Phase 2 & $\begin{array}{l}\text { Chemotherapy before } \\
\text { surgery }\end{array}$ & NCT03399071 & 2018 & Recruiting \\
\hline \multirow[t]{6}{*}{ Atezolizumab } & Phase 2 & Chemoradiotherapy & NCT03087864 & 2017 & $\begin{array}{l}\text { Completed in } 2020 \text {, but no } \\
\text { results published }\end{array}$ \\
\hline & Phase 1 & Chemoradiotherapy & NCT03784326 & 2018 & Recruiting \\
\hline & Phase 2 & Chemotherapy & NCT03448835 & 2018 & Recruiting \\
\hline & Phase $1 / 2$ & Cabozantinib & NCT03170960 & 2017 & Recruiting \\
\hline & Phase $1 / 2$ & KY1044 & NCT03829501 & 2019 & Recruiting \\
\hline & Phase $1 / 2$ & DKN-01 & NCT04166721 & 2019 & Recruiting \\
\hline
\end{tabular}


Table I. Continued.

\begin{tabular}{|c|c|c|c|c|c|}
\hline $\begin{array}{l}\text { Immuno- } \\
\text { therapeutic } \\
\text { option }\end{array}$ & $\begin{array}{c}\text { Stage of } \\
\text { development }\end{array}$ & Combined with & $\begin{array}{l}\text { ClinicalTrials } \\
\text { gov.identifier }\end{array}$ & $\begin{array}{l}\text { Start } \\
\text { time }\end{array}$ & Current status \\
\hline \multicolumn{6}{|c|}{ Immune checkpoint inhibitor treatment } \\
\hline \multirow[t]{12}{*}{ Durvalumab } & Phase 2 & Chemoradiotherapy & NCT02962063 & 2016 & Recruiting \\
\hline & Phase 2 & Chemoradiotherapy & NCT03777813 & 2018 & Recruiting \\
\hline & Phase 2 & $\begin{array}{l}\text { Chemoradiotherapy + } \\
\text { chemotherapy }\end{array}$ & NCT02735239 & 2016 & Active but not recruiting \\
\hline & Phase 2 & After chemoradiotherapy & NCT04054518 & 2019 & Not yet recruiting \\
\hline & Phase 2 & $\begin{array}{l}\text { After chemoradiotherapy } \\
+ \text { surgery }\end{array}$ & NCT02639065 & 2015 & Active but not recruiting \\
\hline & Phase 2 & $\begin{array}{l}\text { After chemoradiotherapy } \\
+ \text { surgery }\end{array}$ & NCT02520453 & 2015 & Active but not recruiting \\
\hline & Phase 2 & $\begin{array}{l}\text { Chemoradiotherapy } \\
+ \text { Tremelimumab }\end{array}$ & NCT03377400 & 2017 & Active but not recruiting \\
\hline & Phase 1 & $\begin{array}{l}\text { Chemotherapy }+ \\
\text { Tremelimumab }\end{array}$ & NCT02658214 & 2013 & Active but not recruiting \\
\hline & Phase 2 & Tremelimumab & NCT03292250 & 2017 & Recruiting \\
\hline & Phase 2 & Tremelimumab & NCT03982173 & 2019 & Not yet recruiting \\
\hline & Phase 2 & Tremelimumab & NCT04159974 & 2019 & Recruiting \\
\hline & Phase $1 / 2$ & Tremelimumab + SBRT & NCT03212469 & 2017 & Recruiting \\
\hline \multirow[t]{2}{*}{ SHR-1316 } & Phase 2 & Chemotherapy & NCT03732508 & 2018 & Recruiting \\
\hline & Phase 2 & Nimotuzumab & NCT03766178 & 2019 & Not yet recruiting \\
\hline
\end{tabular}

Adoptive T-cell therapy

\begin{tabular}{|c|c|c|c|c|}
\hline Phase 1 & $\begin{array}{l}\text { HER2Bi-armed T- } \\
\text { cells + IL-2 }\end{array}$ & NCT02662348 & 2016 & Unknown \\
\hline Phase $1 / 2$ & $\begin{array}{l}\text { CAR-T combined with } \\
\text { PD-1 knockout T-cells }\end{array}$ & NCT03706326 & 2018 & Recruiting \\
\hline Phase 1 & $\begin{array}{l}\text { CAR-T combined with } \\
\text { CAdVEC } \\
\text { (oncolytic adenovirus) }\end{array}$ & NCT03740256 & 2018 & Recruiting \\
\hline Phase 1 & $\begin{array}{l}\text { TCR-T + } \\
\text { Cyclophosphamide } \\
\text { + Fludarabine }\end{array}$ & NCT02869217 & 2016 & Recruiting \\
\hline Phase 1 & $\begin{array}{l}\mathrm{TCR}-\mathrm{T}+ \\
+ \text { Fludarabine }\end{array}$ & NCT02366546 & 2015 & Active but not recruiting \\
\hline Phase 1 & $\begin{array}{l}\text { Cyclophosphamide } \\
\text { TCR-T + + Fludarabine } \\
\text { Cyclophosphamide }\end{array}$ & NCT02096614 & 2017 & Unknown \\
\hline Phase 1 & TCR-T + Radiotherapy & NCT03132922 & 2017 & Recruiting \\
\hline Phase 1 & TCR-T + Trastuzumab & NCT03680560 & 2018 & Suspended by the sponsor \\
\hline
\end{tabular}

Peptide vaccine

\begin{tabular}{|c|c|c|c|c|}
\hline Phase 1 & + Chemotherapy & NCT00632333 & 2011 & Unknown \\
\hline Phase 2 & $\begin{array}{l}+ \text { Toll-like receptor } \\
9 \text { agonist }\end{array}$ & NCT00669292 & 2010 & Unknown \\
\hline Phase 2 & $\begin{array}{l}+ \text { Granulocyte- } \\
\text { macrophage colony } \\
\text { stimulating factor }\end{array}$ & NCT00012246 & 2013 & $\begin{array}{l}\text { Terminated without any } \\
\text { published results }\end{array}$ \\
\hline
\end{tabular}


Table I. Continued.

$\begin{array}{lllll}\begin{array}{l}\text { Immuno- } \\ \text { therapeutic }\end{array} & \begin{array}{c}\text { Stage of } \\ \text { development }\end{array} & \text { Combined with } & \begin{array}{l}\text { ClinicalTrials } \\ \text { gov.identifier }\end{array} & \begin{array}{l}\text { Start } \\ \text { time }\end{array}\end{array}$

Oncolytic virus

\begin{tabular}{|c|c|c|c|c|c|}
\hline $\begin{array}{l}\text { Oncolytic } \\
\text { measles virus }\end{array}$ & Phase 1 & $\begin{array}{l}+5 \text {-Fluorocytosine }+ \text { anti- } \\
\text { PD- } 1 \text { checkpoint inhibitor }\end{array}$ & NCT04195373 & 2020 & Withdrawn \\
\hline \multirow[t]{3}{*}{$\begin{array}{l}\text { Oncolytic } \\
\text { adenovirus }\end{array}$} & Phase 1 & $\begin{array}{l}\text { CAdVEC combined } \\
\text { with CAR-T }\end{array}$ & NCT03740256 & 2018 & Recruiting \\
\hline & Phase 1 & $\begin{array}{l}\text { Telomelysin + } \\
\text { radiotherapy }\end{array}$ & NCT03213054 & 2017 & Recruiting \\
\hline & Phase 2 & $\begin{array}{l}\text { Telomelysin }+ \\
\text { Pembrolizumab }\end{array}$ & NCT03921021 & 2019 & Recruiting \\
\hline
\end{tabular}

ClinicalTrials.gov was accessed in November, 2020.

is expressed, immunological tolerance exists and only in the case of a PD- $1^{+}$tumour microenvironment containing $\mathrm{CD}^{+}$ T-cells an adoptive immune resistance is present that is most likely to respond to immune checkpoint inhibitor therapy (79).

\section{Adoptive T-cell therapy}

Adoptive T-cell therapy is a personalized approach of immunotherapy. T-cells are collected from the tumour or peripheral blood of a patient and the isolated T-cells are stimulated in vitro with IL-2. After this ex-vivo expansion, the cancer patient receives his own autologous immune cells as an infusion (80). In addition, T-cells can be also genetically modified after collection from the patient either by introducing chimeric antigen receptor (CAR T-cells) or transducing antigen-specific TCR cells (TCR T-cells). In all cases, the expanded or modified T-cells exert an improved tumour-specific immunity (81-83). In several trials, a regression of tumours has been demonstrated following persistent adoptive T-cell therapy $(84,85)$. In a first clinical trial based on adoptive T-cell therapy for patients with recurrent or advanced oesophageal cancer, the patients received (on a fortnight basis) activated T-cells administered into primary tumours or metastatic lymph nodes; this therapy was found to be safe and in one third of the patients, a significant tumour regression was observed (86). In another study, based on TCR T-cells, oesophageal cancer patients with minimal tumours survived $>27$ months; nevertheless, after 2 months of treatment, several patients exhibited tumour progression even if the autologous T-cells persist for a long period of time; therefore, TCR T-cell therapy appears to have a benefit only for oesophageal cancer patients with minimal lesions (87).

\section{Peptide vaccine}

Peptide vaccines are therapeutic cancer vaccines which aim to increase immunogenic cancer-specific antigens, leading to the activation of cancer antigen-specific T-cells in vivo $(59,76,88)$. For the successful use of peptide vaccines, the characterization of tumour-specific T-cells and the use of immunogenic tumour-associated antigens are a prerequisite (89). As tumour-associated antigens, either recombinant short peptides, whole-cell tumour lysates or full-length proteins can be used $(90,91)$. The length of the used peptide has at least in part an influence on the efficiency of the immune response (92). It has been well-established that short peptides composed of 8-11 amino acids induce major histocompatibility complex (MHC) class-I-restricted antigen-specific $\mathrm{CD}^{+} \mathrm{T}$-cell reaction via direct binding to human leukocyte antigen (HLA)-I molecules (93). By contrast, longer peptides (25-50 amino acids) are usually presented by MHC class-I and class-II molecules on antigen-presenting cells to $\mathrm{CD}^{+}$or $\mathrm{CD} 4^{+} \mathrm{T}$-cell, respectively (94). This results in a broader and longer lasting immune response by generating cytotoxic T-lymphocytes as well as long-living memory $\mathrm{CD}^{+}$ T-cells (95).

In a modified approach, dendritic cells isolated from the peripheral blood of a cancer patient are presented to tumour-associated antigens ex vivo and after loading with the antigens the dendritic cells, are re-injected into patients $(91,96)$. This strategy was evaluated in a pre-clinical study as possible novel treatment option for oesophageal tumours (97). Dendritic cells from oesophageal cancer patients have been pulsed with Wilms' tumour 1 peptide ex vivo and used as a vaccine. The patients were treated in parallel with the chemotherapeutic agent, picibanil. In this exploratory study, 15 patients were included; the median progression-free survival and overall survival were 4.1 and 7.0 months, respectively. This treatment was well-tolerated and no severe adverse events related to the vaccinations were observed (97). Based on this promising result, a phase II clinical trial is in preparation.

Even with the first-generation of peptide vaccines which have been based on highly expressed non-mutant tumour-associated antigens of tumour cells [such as melanoma antigen gene (MAGE) and New York oesophageal squamous cell carcinoma-1 (NY-ESO-1) proteins] an immune response was induced and led to clinical positive effect (98-100). The advantage of these peptides is that they are only expressed in male 


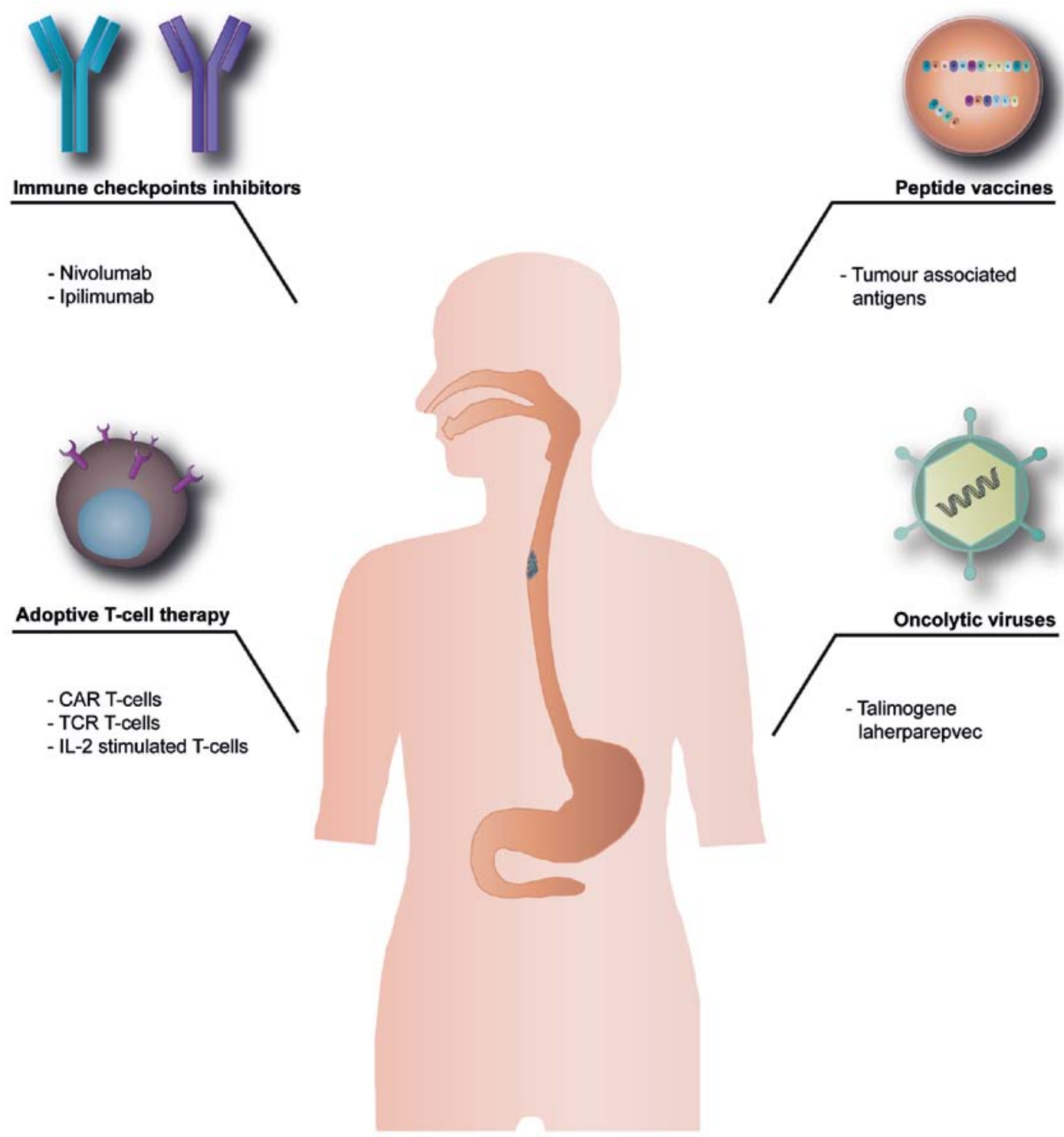

Figure 1. Immunotherapy approaches in oesophageal cancer. Illustration of the different immunotherapy approaches that have been studied thus far in the context of oesophageal cancer. CAR, chimeric antigen receptor; TCR, T-cell receptor; IL-2, interleukin 2.

germ-line cells and placenta under physiological conditions; however, a number of tumours, among these oesophageal cancer, express these proteins as well. Therefore, they represent very promising targets for cancer immunotherapy (101-103).

The second-generation of peptide vaccines is an effort for a more personalized medicine with the aim of targeting mutated antigens that are patient-specific. In this approach, mutations which have been accumulated during tumour development are the basis for the vaccine generation (104). In the context of oesophageal cancer, a large number of genetic mutations are present which result in specific neo-antigens (105). The main challenge is to identify mutated epitopes derived from tumour neo-antigens for developing a patient-specific vaccine $(106,107)$. The vaccine peptides are patient-specific and they differ completely among patients. Therefore, batch production will not be possible and it will never become a conventional drug (104). The advantage is that neo-antigen vaccines result in a potent $\mathrm{T}$-cell response and induce a new population of specific T-cells in cancer patients that are able to kill cancer cells without damaging healthy tissues $(104,108,109)$. Furthermore, pre-clinical trials are forthcoming with an aim to induce the T-cell response by ribonucleic acid (RNA)-based vaccine coding for multiple neo-epitopes (110). Another novel strategy combines the use of long-peptide vaccines with checkpoint inhibitor administration (111). The aim in both cases, is to increase the repertoire of $\mathrm{CD}^{+}$and $\mathrm{CD}^{+} \mathrm{T}$-cell directed against the tumour. These personalized approaches have the potential to offer novel therapeutic options with high specificity and low toxicity for cancer patients who are resistant to current therapies.

Peptide vaccines have been used in several clinical trials in patients with oesophageal squamous carcinoma. Different peptides have been administered simultaneously to patients, which resulted in a significant induced $\mathrm{CD} 8^{+} \mathrm{T}$-cell response. Clinical benefit, as well as an increased overall survival was observed in the majority of patients $(112,113)$. Peptide vaccinations can be combined with other therapeutic options in patients with oesophageal tumours. One example is the use of a peptide vaccine to suppress the recurrence of oesophageal cancer following curative resection. In a previous study, the 
5-year relapse-free survival of oesophageal cancer patients was $44.6 \%$ in patients that received the vaccination compared to the ones that did not receive the vaccination (31.6\% relapse-free survival) (114). Of special interest is the peptide vaccine, S-588410, which is composed of 5 HLA-A*2402-restricted epitope peptides derived from the onco-antigens, DEPDC1, MPHOSPH1, URLC10, CDCA1 and KOC1. All these antigens are up-regulated in the context of oesophageal cancer $(115,116)$. In previous studies, it was proven that each of these 5 peptides has the capacity to induce a peptide-specific activation of $\mathrm{CD}^{+} \mathrm{T}$-cells in different tumours, among these oesophageal cancer $(112,113,117,118)$. In an exploratory study based on 15 patients with oesophageal tumours, an increased immune response in tumour tissue was observed following vaccination with S-588410. Following a median of 5 injections of S-588410, peptide-specific CD8 ${ }^{+} \mathrm{T}$-cells for all peptides included in this vaccination were induced in all patients. The number of functional T-lymphocytes $\left(\mathrm{CD}^{+}\right.$and $\mathrm{CD}^{+} \mathrm{T}$-cells) was found to be increased in blood, as well as in tumour biopsies. In parallel, a higher PD-L1 expression in the tumour microenvironment was observed (115). Most probably, the increased PD-L1 expression was related to interferon (IFN)- $\gamma$ produced by infiltrated $\mathrm{CD} 8^{+} \mathrm{T}$-cells into the tumour area. The accumulation of effective T-cells and IFN- $\gamma$ production in the tumour microenvironment most probably favour the change from an immune 'desert' into an immune-inflamed tumour microenvironment (93). It is tempting to speculate about the therapeutic potential of combining peptide vaccines, such as S-588410 with immune-checkpoint inhibitors in patients with oesophageal cancer $(54,79)$.

\section{Oncolytic viruses}

Oncolytic virus therapy is still in its infancy, but it has already proven its potential. In general, oncolytic viruses infect and replicate selectively in tumour cells and induce tumour cell lysis $(119,120)$. Talimogene laherparepvec is the first FDA-approved oncolytic viral therapy for the treatment of patients with advanced melanoma (121). Recently, the efficacy of a telomerase-specific oncolytic virus (telomelysin OBP-301) in combination with radiotherapy was investigated in a Phase I/II study for the treatment of elderly patients with oesophageal squamous cell carcinoma. According to the first results, this viral therapy was well-tolerated and demonstrated efficient tumour regression $(122,123)$. Based on this success, several other clinical trials with various oncolytic viruses for the treatment of patients with oesophageal cancer are ongoing (Table I).

\section{Conclusion and perspectives}

In oesophageal cancer, as in most other tumour diseases, the therapeutic options are limited and therapeutic success is only achieved for a short period of time before resistance appears. Therefore, novel therapeutic options, such as the addition of immunotherapy to the treatment of tumours are an urgent need. Albeit some success of immunotherapy in oesophageal cancer treatment and the approval of pembrolizumab and nivolumab by the FDA, it is noteworthy to mention that immunotherapy is often associated with severe toxic side-effects; the most frequent ones are cutaneous, gastrointestinal, endocrine and hepatic toxicity. Therefore, a careful monitoring and follow-up of patients under immunotherapy is required and if necessary, the patient must receive effective measures to manage the side-effects. An advantage for patients with oesophageal cancer could be a combination of immunotherapy with surgery, chemotherapy and radiotherapy. Recently, the advantage from radiotherapy in parallel with immune checkpoint inhibitor treatment was already demonstrated (124).

A prerequisite for improving the success and efficiency of immunotherapy is the knowledge about robust biomarkers predicting clinical benefit before treatment and enabling stratification of oesophageal cancer patients in such a manner that the best possible immunotherapy can be applied to each patient. One possibility could be the multiplexed immunohistochemical staining of adaptive immune (CD3, CD4, CD8 and CD45RO) and immune checkpoint biomarkers [inducible T-cell costimulatory molecule (ICOS), indoleamine-2,3-dioxygenase-1 (IDO-1), PD-L1 and PD-1] in combination with digital pathology quantitation (125). Furthermore, it is well-established that immunotherapies are resulting in an increased tumour burden and/or emergence of new tumour lesions in the short-term. Therefore, the currently used evaluation system for therapeutically success is most probably not applicable for immunotherapies; thus, it may be prudent to consider a different system for this novel type of therapy.

\section{Acknowledgements}

Not applicable.

\section{Funding}

No funding was received.

\section{Availability of data and materials}

Not applicable.

\section{Authors' contributions}

$\mathrm{JCH}, \mathrm{AL}$ and $\mathrm{NV}$ were involved in the conceptualization of the study. JCH, MG, MR and AL were involved in the writing and preparation of the original draft. JCH, NV, MBM and AFO were involved in the writing, reviewing and editing of the manuscript. All authors have read and agreed to the published version of the manuscript.

\section{Ethics approval and consent to participate}

Not applicable.

\section{Patient consent for publication}

Not applicable.

\section{Competing interests}

NV received speaker honorarium from the companies, Bayer, Eli-Lilly, Pfizer and Merck. The funders had no role in the design of the study; in the collection, analyses, or interpretation 
of data; in the writing of the manuscript, or in the decision to publish the results. All other authors (AL, MR, MG, MBM, $\mathrm{AFO}$ and $\mathrm{JCH}$ ) declare that they have no competing interests.

\section{References}

1. de Vos-Geelen J, Hoebers FJP, Geurts SME, Hoeben A, de Greef BTA, Voncken FEM, Bogers JHA, Braam PM, Muijs CKT, de Jong MA, et al: A national study to assess outcomes of definitive chemoradiation regimens in proximal esophageal cancer. Acta Oncol 59: 895-903, 2020.

2. Sung H, Ferlay J, Siegel RL, Laversanne M, Soerjomataram I, Jemal A and Bray F: Global cancer statistics 2020: GLOBOCAN estimates of incidence and mortality worldwide for 36 cancers in 185 countries. CA Cancer J Clin: Feb 4, 2021 (Epub ahead of print)

3. Lin Y, Totsuka Y, He Y, Kikuchi S, Qiao Y, Ueda J, Wei W, Inoue $\mathrm{M}$ and Tanaka $\mathrm{H}$ : Epidemiology of esophageal cancer in Japan and China. J Epidemiol 23: 233-242, 2013.

4. Napier KJ, Scheerer M and Misra S: Esophageal cancer: A Review of epidemiology, pathogenesis, staging workup and treatment modalities. World J Gastrointest Oncol 6: 112-120, 2014

5. Bartley AN, Washington MK, Ventura CB, Ismaila $\mathrm{N}$, Colasacco C, Benson AB III, Carrato A, Gulley ML, Jain D, Kakar S, et al: HER2 testing and clinical decision making in gastroesophageal adenocarcinoma: Guideline from the college of American pathologists, American society for clinical pathology, and American society of clinical oncology. Arch Pathol Lab Med 140: 1345-1363, 2016

6. Bang YJ, Van Cutsem E, Feyereislova A, Chung HC, Shen L, Sawaki A, Lordick F, Ohtsu A, Omuro Y, Satoh T, et al: Trastuzumab in combination with chemotherapy versus chemotherapy alone for treatment of HER2-positive advanced gastric or gastro-oesophageal junction cancer (ToGA): A phase 3, open-label, randomised controlled trial. Lancet 376: 687-697, 2010.

7. Lordick F, Mariette C, Haustermans K, Obermannova R, Arnold D and ESMO Guidelines Committee: Oesophageal cancer: ESMO Clinical Practice Guidelines for diagnosis, treatment and follow-up. Ann Oncol 27 (Suppl 5): v50-v57, 2016.

8. Brar G and Shah MA: The role of pembrolizumab in the treatment of PD-L1 expressing gastric and gastroesophageal junction adenocarcinoma. Therap Adv Gastroenterol 12: 1756284819869767, 2019.

9. Le Bras GF, Farooq MH, Falk GW and Andl CD: Esophageal cancer: The latest on chemoprevention and state of the art therapies. Pharmacol Res 113(Pt A): 236-244, 2016.

10. Short MW, Burgers KG and Fry VT: Esophageal cancer. Am Fam Physician 95: 22-28, 2017.

11. Kitagawa Y, Uno T, Oyama T, Kato K, Kato H, Kawakubo H, Kawamura O, Kusano M, Kuwano $\mathrm{H}$, Takeuchi $\mathrm{H}$, et al: Esophageal cancer practice guidelines 2017 edited by the Japan esophageal society: Part 2. Esophagus 16: 25-43, 2019.

12. Wang T, Yu J, Liu M, Chen Y, Zhu C, Lu L, Wang M, Min L, Liu X, Zhang X, et al: The benefit of taxane-based therapies over fluoropyrimidine plus platinum (FP) in the treatment of esophageal cancer: A meta-analysis of clinical studies. Drug Des Devel Ther 13: 539-553, 2019.

13. Zhang Y: Epidemiology of esophageal cancer. World J Gastroenterol 19: 5598-5606, 2013.

14. Blot WJ: Invited commentary: More evidence of increased risks of cancer among alcohol drinkers. Am J Epidemiol 150 1138-1140; discussion 1141, 1999.

15. Guanrei Y and Songliang Q: Endoscopic surveys in high-risk and low-risk populations for esophageal cancer in China with special reference to precursors of esophageal cancer. Endoscopy 19: 91-95, 1987.

16. Lagergren $J$ and Lagergren P: Recent developments in esophageal adenocarcinoma. CA Cancer J Clin 63: 232-248, 2013.

17. Duggan C, Onstad L, Hardikar S, Blount PL, Reid BJ and Vaughan TL: Association between markers of obesity and progression from Barrett's esophagus to esophageal adenocarcinoma. Clin Gastroenterol Hepatol 11: 934-943, 2013.

18. Carr JS, Zafar SF, Saba N, Khuri FR and El-Rayes BF: Risk factors for rising incidence of esophageal and gastric cardia adenocarcinoma. J Gastrointest Cancer 44: 143-151, 2013.

19. Lofdahl HE, Lu Y, Lagergren $P$ and Lagergren J: Risk factors for esophageal adenocarcinoma after antireflux surgery. Ann Surg 257: 579-582, 2013.
20. Mao WM, Zheng WH and Ling ZQ: Epidemiologic risk factors for esophageal cancer development. Asian Pac J Cancer Prev 12: 2461-2466, 2011.

21. D'Onofrio V, Bovero E and Iaquinto G: Characterization of acid and alkaline reflux in patients with Barrett's esophagus. G.O.S.P.E. Operative Group for the study of Esophageal Precancer. Dis Esophagus 10: 16-22; discussion 22-3, 1997.

22. Fassan M, Realdon S, Cascione L, Hahne JC, Munari G, Guzzardo V, Arcidiacono D, Lampis A, Brignola S, Dal Santo L, et al: Circulating microRNA expression profiling revealed miR-92a-3p as a novel biomarker of Barrett's carcinogenesis. Pathol Res Pract 216: 152907, 2020.

23. Lin J, Zeng R, Cao W, Luo R, Chen J and Lin Y: Hot beverage and food intake and esophageal cancer in southern China. Asian Pac J Cancer Prev 12: 2189-2192, 2011.

24. Nieman KM, Romero IL, Van Houten B and Lengyel E: Adipose tissue and adipocytes support tumorigenesis and metastasis. Biochim Biophys Acta 1831: 1533-1541, 2013.

25. Lawrence MS, Stojanov P, Polak P, Kryukov GV, Cibulskis K, Sivachenko A, Carter SL, Stewart C, Mermel CH, Roberts SA, et al: Mutational heterogeneity in cancer and the search for new cancer-associated genes. Nature 499: 214-218, 2013.

26. Ratti M, Lampis A, Hahne JC, Passalacqua R and Valeri N: Microsatellite instability in gastric cancer: Molecular bases, clinical perspectives, and new treatment approaches. Cell Mol Life Sci 75: 4151-4162, 2018.

27. Lin EW, Karakasheva TA, Hicks PD, Bass AJ and Rustgi AK: The tumor microenvironment in esophageal cancer. Oncogene 35: 5337-5349, 2016.

28. Ammannagari $\mathrm{N}$ and Atasoy A: Current status of immunotherapy and immune biomarkers in gastro-esophageal cancers. J Gastrointest Oncol 9: 196-207, 2018.

29. Le DT, Uram JN, Wang H, Bartlett BR, Kemberling H, Eyring AD, Skora AD, Luber BS, Azad NS, Laheru D, et al: PD-1 Blockade in tumors with Mismatch-Repair deficiency. N Engl J Med 372: 2509-2520, 2015.

30. Kim WK, Park M, Park M, Kim YJ, Shin N, Kim HK, You KT and Kim H: Identification and selective degradation of neopeptide-containing truncated mutant proteins in the tumors with high microsatellite instability. Clin Cancer Res 19: 3369-3382, 2013.

31. Puzzoni M, Silvestris N, Leone F, Giampieri R, Faloppi L, Demurtas L, Dell'Aquila E, Marino D, Brunetti O, Garattini SK, et al: The immune revolution in gastrointestinal tumours: Leading the way or just following? Target Oncol 11: 593-603, 2016.

32. Li P, Xu W, Liu F, Zhu H, Zhang L, Ding Z, Liang H and Song J: The emerging roles of IDO2 in cancer and its potential as a therapeutic target. Biomed Pharmacother 137: 111295, 2021.

33. Zhou H, Jiang M, Yuan H, Ni W and Tai G: Dual roles of myeloid-derived suppressor cells induced by Toll-like receptor signaling in cancer. Oncol Lett 21: 149, 2021.

34. Abou Khouzam R, Brodaczewska K, Filipiak A, Zeinelabdin NA, Buart S, Szczylik C, Kieda C and Chouaib S: Tumor hypoxia regulates immune Escape/Invasion: Influence on angiogenesis and potential impact of hypoxic biomarkers on cancer therapies. Front Immunol 11: 613114, 2021.

35. Gajewski TF, Schreiber H and Fu YX: Innate and adaptive immune cells in the tumor microenvironment. Nat Immunol 14: 1014-1022, 2013.

36. Ando M, Ito M, Srirat T, Kondo T and Yoshimura A: Memory $\mathrm{T}$ cell, exhaustion, and tumor immunity. Immunol Med 43: 1-9, 2020.

37. Chen DS and Mellman I: Oncology meets immunology: The cancer-immunity cycle. Immunity 39: 1-10, 2013.

38. Hahne JC, Meyer SR, Gambaryan S, Walter U, Dietl J, Engel JB and Honig A: Immune escape of AKT overexpressing ovarian cancer cells. Int J Oncol 42: 1630-1635, 2013.

39. Boutet P, Aguera-Gonzalez S, Atkinson S, Pennington CJ, EdwardsDR,MurphyG,ReyburnHT and Valés-Gómez M:Cutting edge: The metalloproteinase ADAM17/TNF-alpha-converting enzyme regulates proteolytic shedding of the MHC class I-related chain B protein. J Immunol 182: 49-53, 2009.

40. Waldhauer I, Goehlsdorf D, Gieseke F, Weinschenk T, Wittenbrink M, Ludwig A, Stevanovic S, Rammensee HG and Steinle A: Tumor-associated MICA is shed by ADAM proteases. Cancer Res 68: 6368-6376, 2008.

41. Pardoll DM: The blockade of immune checkpoints in cancer immunotherapy. Nat Rev Cancer 12: 252-264, 2012. 
42. Ricklefs FL, Alayo Q, Krenzlin H, Mahmoud AB, Speranza MC, Nakashima H, Hayes JL, Lee K, Balaj L, Passaro C, et al: Immune evasion mediated by PD-L1 on glioblastoma-derived extracellular vesicles. Sci Adv 4: eaar2766, 2018.

43. Theodoraki MN, Yerneni SS, Hoffmann TK, Gooding WE and Whiteside TL: Clinical significance of PD-L1(+) exosomes in plasma of head and neck cancer patients. Clin Cancer Res 24: 896-905, 2018

44. Corthay A: How do regulatory T cells work? Scand J Immunol 70: 326-336, 2009.

45. Romano M, Fanelli G, Albany CJ, Giganti G and Lombardi G Past, present, and future of regulatory $\mathrm{T}$ Cell therapy in transplantation and autoimmunity. Front Immunol 10: 43, 2019.

46. Togashi Y, Shitara K and Nishikawa H: Regulatory T cells in cancer immunosuppression-implications for anticancer therapy. Nat Rev Clin Oncol 16: 356-371, 2019.

47. Engel JB, Honig A, Kapp M, Hahne JC, Meyer SR, Dietl J and Segerer SE: Mechanisms of tumor immune escape in triple-negative breast cancers (TNBC) with and without mutated BRCA 1 Arch Gynecol Obstet 289: 141-147, 2014.

48. Gabrilovich DI and Nagaraj S: Myeloid-derived suppressor cells as regulators of the immune system. Nat Rev Immunol 9: 162-174, 2009.

49. Gabrilovich DI: Myeloid-Derived suppressor cells. Cancer Immunol Res 5: 3-8, 2017.

50. Karakasheva TA, Dominguez GA, Hashimoto A, Lin EW, Chiu C, Sasser K, Lee JW, Beatty GL, Gabrilovich DI and Rustgi AK CD38+ M-MDSC expansion characterizes a subset of advanced colorectal cancer patients. JCI Insight 3: e97022, 2018.

51. Shi T, Ma Y, Yu L, Jiang J, Shen S, Hou Y and Wang T: Cancer immunotherapy: A focus on the regulation of immune checkpoints. Int J Mol Sci 19: 1389, 2018.

52. Kim ES, Kim JE, Patel MA, Mangraviti A, Ruzevick J and Lim M: Immune checkpoint modulators: An emerging antiglioma armamentarium. J Immunol Res 2016: 4683607, 2016.

53. Vivaldi C, Catanese S, Massa V, Pecora I, Salani F, Santi S, Lencioni M, Vasile E, Falcone A and Fornaro L: Immune checkpoint inhibitors in esophageal cancers: Are we finally finding the right path in the mist? Int J Mol Sci 21: 1658, 2020.

54. Sharma P and Allison JP: The future of immune checkpoint therapy. Science 348: 56-61, 2015.

55. Topalian SL, Drake CG and Pardoll DM: Immune checkpoint blockade: A common denominator approach to cancer therapy. Cancer Cell 27: 450-461, 2015.

56. Disis ML: Mechanism of action of immunotherapy. Semin Oncol 41 (Suppl 5): S3-S13, 2014.

57. Senju H, Kumagai A, Nakamura Y, Yamaguchi H, Nakatomi K, Fukami S, Shiraishi K, Harada Y, Nakamura M, Okamura H, et al Effect of IL-18 on the expansion and phenotype of human natural killer cells: Application to cancer immunotherapy. Int J Biol Sci 14: 331-340, 2018.

58. Patel SP and Kurzrock R: PD-L1 expression as a predictive biomarker in cancer immunotherapy. Mol Cancer Ther 14 847-856, 2015.

59. Mimura K, Yamada L, Ujiie D, Hayase S, Tada T, Hanayama H, TharMin AK, Shibata M,Momma T, Saze Z, et al: Immunotherapy for esophageal squamous cell carcinoma: A review. Fukushima J Med Sci 64: 46-53, 2018.

60. Redman JM, Gibney GT and Atkins MB: Advances in immunotherapy for melanoma. BMC Med 14: 20, 2016

61. Figueroa-Protti L, Soto-Molinari R, Calderon-Osorno M, Mora J and Alpizar-Alpizar W: Gastric cancer in the Era of immune checkpoint blockade. J Oncol 2019: 1079710, 2019.

62. Brahmer JR, Tykodi SS, Chow LQ, Hwu WJ, Topalian SL, Hwu P, Drake CG, Camacho LH, Kauh J, Odunsi K, et al: Safety and activity of anti-PD-L1 antibody in patients with advanced cancer. N Engl J Med 366: 2455-2465, 2012.

63. Marchetti A, Di Lorito A and Buttitta F: Why anti-PD1/PDL1 therapy is so effective? Another piece in the puzzle. J Thorac Dis 9: 4863-4866, 2017.

64. Akinleye A and Rasool Z: Immune checkpoint inhibitors of PD-L1 as cancer therapeutics. J Hematol Oncol 12: 92, 2019.

65. Hamid O, Robert C, Daud A, Hodi FS, Hwu WJ, Kefford R, Wolchok JD, Hersey P, Joseph RW, Weber JS, et al: Safety and tumor responses with lambrolizumab (anti-PD-1) in melanoma. N Engl J Med 369: 134-144, 2013

66. Robert C, Ribas A, Wolchok JD, Hodi FS, Hamid O, Kefford R, Weber JS, Joshua AM, Hwu WJ, Gangadhar TC, et al: Anti-progra mmed-death-receptor-1 treatment with pembrolizumab in ipilimumab-refractory advanced melanoma: A randomised dose-comparison cohort of a phase 1 trial. Lancet 384: 1109-1117, 2014.
67. Maleki Vareki S, Garrigos C and Duran I: Biomarkers of response to PD-1/PD-L1 inhibition. Crit Rev Oncol Hematol 116: 116-124, 2017.

68. Kato R, Yamasaki M, Urakawa S, Nishida K, Makino T, Morimoto-Okazawa A, Kawashima A, Iwahori K, Suzuki S, Ueda R, et al: Increased Tim-3(+) T cells in PBMCs during nivolumab therapy correlate with responses and prognosis of advanced esophageal squamous cell carcinoma patients. Cancer Immunol Immunother 5467: 1673-1683, 2018.

69. Brahmer JR, Rodriguez-Abreu D, Robinson AG, Hui R, Csőszi T, Fülöp A, Gottfried M, Peled N, Tafreshi A, Cuffe S, et al: Health-related quality-of-life results for pembrolizumab versus chemotherapy in advanced, PD-L1-positive NSCLC (KEYNOTE-024): A multicentre, international, randomised, open-label phase 3 trial. Lancet Oncol 18: 1600-1609, 2017.

70. Seiwert TY, Burtness B, Mehra R, Weiss J, Berger R, Eder JP, Heath K, McClanahan T, Lunceford J, Gause C, et al: Safety and clinical activity of pembrolizumab for treatment of recurrent or metastatic squamous cell carcinoma of the head and neck (KEYNOTE-012): An open-label, multicentre, phase 1b trial. Lancet Oncol 17: 956-965, 2016.

71. Fuchs CS, Doi T, Jang RW, Muro K, Satoh T, Machado M, Sun W, Jalal SI, Shah MA, Metges JP, et al: Safety and efficacy of pembrolizumab monotherapy in patients with previously treated advanced gastric and gastroesophageal junction cancer: Phase 2 Clinical KEYNOTE-059 Trial. JAMA Oncol 4: e180013, 2018.

72. Doi T, Piha-Paul SA, Jalal SI, Saraf S, Lunceford J, Koshiji M and Bennouna J: Safety and antitumor activity of the Anti-Programmed Death-1 antibody pembrolizumab in patients with advanced esophageal carcinoma. J Clin Oncol 36: 61-67, 2018.

73. Hamanishi J, Mandai M, Ikeda T, Minami M, Kawaguchi A, Murayama T, Kanai M, Mori Y, Matsumoto S, Chikuma S, et al: Safety and antitumor activity of Anti-PD-1 Antibody, Nivolumab, in patients with platinum-resistant ovarian cancer. J Clin Oncol 33: 4015-4022, 2015.

74. Kato K, Cho BC, Takahashi M, Okada M, Lin CY, Chin K, Kadowaki S, Ahn MJ, Hamamoto Y, Doki Y, et al: Nivolumab versus chemotherapy in patients with advanced oesophageal squamous cell carcinoma refractory or intolerant to previous chemotherapy (ATTRACTION-3): A multicentre, randomised, open-label, phase 3 trial. Lancet Oncol 20: 1506-1517, 2019.

75. Das R, Verma R, Sznol M, Boddupalli CS, Gettinger SN Kluger H, Callahan M, Wolchok JD, Halaban R, Dhodapkar MV and Dhodapkar KM: Combination therapy with anti-CTLA-4 and anti-PD-1 leads to distinct immunologic changes in vivo. J Immunol 194: 950-959, 2015.

76. Tanaka T, Nakamura $J$ and Noshiro H: Promising immunotherapies for esophageal cancer. Expert Opin Biol Ther 17: 723-733, 2017.

77. Janjigian YY, Bendell J, Calvo E, Kim JW, Ascierto PA, Sharma P, Ott PA, Peltola K, Jaeger D, Evans J, et al: CheckMate-032 study: Efficacy and safety of nivolumab and nivolumab plus ipilimumab in patients with metastatic esophagogastric cancer. J Clin Oncol 36: 2836-2844, 2018.

78. Zhao Y, Yang W, Huang Y, Cui R, Li X and Li B: Evolving roles for Targeting CTLA-4 in cancer immunotherapy. Cell Physiol Biochem 47: 721-734, 2018

79. Darvin P, Toor SM, Sasidharan Nair V and Elkord E: Immune checkpoint inhibitors: Recent progress and potential biomarkers. Exp Mol Med 50: 1-11, 2018

80. Rosenberg SA and Restifo NP: Adoptive cell transfer as personalized immunotherapy for human cancer. Science 348: 62-68, 2015.

81. Alsina M, Moehler M and Lorenzen S: Immunotherapy of esophageal cancer: Current status, many trials and innovative strategies. Oncol Res Treat 41: 266-271, 2018.

82. Miliotou AN and Papadopoulou LC: CAR T-cell Therapy: A New Era in cancer immunotherapy. Curr Pharm Biotechnol 19: 5-18, 2018.

83. Walseng E, Koksal H, Sektioglu IM, Fåne A, Skorstad G, Kvalheim G, Gaudernack G, Inderberg EM and Wälchli S: A TCR-based Chimeric antigen receptor. Sci Rep 7: 10713, 2017.

84. Robbins PF, Dudley ME, Wunderlich J, El-Gamil M, Li YF, Zhou J, Huang J, Powell DJ Jr and Rosenberg SA: Cutting edge: Persistence of transferred lymphocyte clonotypes correlates with cancer regression in patients receiving cell transfer therapy. J Immunol 173: 7125-7130, 2004 
85. Dudley ME, Yang JC, Sherry R, Hughes MS, Royal R, Kammula U, Robbins PF, Huang J, Citrin DE, Leitman SF, et al Adoptive cell therapy for patients with metastatic melanoma: Evaluation of intensive myeloablative chemoradiation preparative regimens. J Clin Oncol 26: 5233-5239, 2008.

86. Toh U, Yamana H, Sueyoshi S, Tanaka T, Niiya F, Katagiri K, Fujita H, Shirozou K and Itoh K: Locoregional cellular immunotherapy for patients with advanced esophageal cancer. Clin Cancer Res 6: 4663-4673, 2000.

87. Kageyama S, Ikeda H, Miyahara Y, Imai N, Ishihara M, Saito K, Sugino S, Ueda S, Ishikawa T, Kokura S, et al: Adoptive Transfer of MAGE-A4 T-cell Receptor Gene-Transduced lymphocytes in patients with recurrent esophageal cancer. Clin Cancer Res 21: 2268-2277, 2015

88. Li W, Joshi MD, Singhania S, Ramsey KH and Murthy AK: Peptide vaccine: Progress and challenges. Vaccines (Basel) 2: 515-536, 2014.

89. Masopust D and Schenkel JM: The integration of T cell migration, differentiation and function. Nat Rev Immunol 13: 309-320, 2013.

90. Aranda F, Vacchelli E, Eggermont A, Galon J, Sautès-Fridman C, Tartour E, Zitvogel L, Kroemer G and Galluzzi L: Trial Watch: Peptide vaccines in cancer therapy. Oncoimmunology 2: e26621, 2013.

91. Tacken PJ, de Vries IJ, Torensma R and Figdor CG: Dendritic-cell immunotherapy: From ex vivo loading to in vivo targeting. Nat Rev Immunol 7: 790-802, 2007.

92. Hos BJ, Tondini E, van Kasteren SI and Ossendorp F: Approaches to improve chemically defined synthetic peptide vaccines. Front Immunol 9: 884, 2018.

93. Chen DS and Mellman I: Elements of cancer immunity and the cancer-immune set point. Nature 541: 321-330, 2017.

94. Blander JM: Regulation of the cell biology of antigen cross-presentation. Annu Rev Immunol 36: 717-753, 2018.

95. Quakkelaar ED and Melief CJ: Experience with synthetic vaccines for cancer and persistent virus infections in nonhuman primates and patients. Adv Immunol 114: 77-106, 2012.

96. Kono K: Current status of cancer immunotherapy. J Stem Cells Regen Med 10: 8-13, 2014

97. Fujiwara S, Wada H, Miyata H, Kawada J, Kawabata R, Nishikawa H, Gnjatic S, Sedrak C, Sato E, Nakamura Y, et al: Clinical trial of the intratumoral administration of labeled DC combined with systemic chemotherapy for esophageal cancer J Immunother 35: 513-521, 2012.

98. Robbins PF, Kassim SH, Tran TL, Crystal JS, Morgan RA, Feldman SA, Yang JC, Dudley ME, Wunderlich JR, Sherry RM, et al: A pilot trial using lymphocytes genetically engineered with an NY-ESO-1-reactive T-cell receptor: Long-term follow-up and correlates with response. Clin Cancer Res 21: 1019-1027, 2015.

99. Daudi S, Eng KH, Mhawech-Fauceglia P, Morrison C, Miliotto A, Beck A, Matsuzaki J, Tsuji T, Groman A, Gnjatic S, et al: Expression and immune responses to MAGE antigens predict survival in epithelial ovarian cancer. PLoS One 9: e104099, 2014

100. Kawabata R, Wada H, Isobe M, Saika T, Sato S, Uenaka A, Miyata H, Yasuda T, Doki Y, Noguchi Y, et al: Antibody response against NY-ESO-1 in CHP-NY-ESO-1 vaccinated patients. Int J Cancer 120: 2178-2184, 2007.

101. Veit JA, Heine D, Thierauf J, Lennerz J, Shetty S, Schuler PJ, Whiteside T, Beutner D, Meyer M, Grünewald I, et al: Expression and clinical significance of MAGE and NY-ESO-1 cancer-testis antigens in adenoid cystic carcinoma of the head and neck. Head Neck 38: 1008-1016, 2016

102. Thomas R,Al-Khadairi G, Roelands J,Hendrickx W, Dermime S, Bedognetti D and Decock J: NY-ESO-1 based immunotherapy of cancer: Current perspectives. Front Immunol 9: 947, 2018.

103. Bujas T, Marusic Z, Peric Balja M, Mijic A, Kruslin B and Tomas D: MAGE-A3/4 and NY-ESO-1 antigens expression in metastatic esophageal squamous cell carcinoma. Eur J Histochem 55: e7, 2011

104. Zhang H, Zhou X, Liu D, Zhu Y, Ma Q and Zhang Y: Progress and challenges of poersonalized neoantigens in the clinical treatment of tumors. Med Drug Disc 6: 100030, 2020.

105. Huang TX and Fu L: The immune landscape of esophageal cancer. Cancer Commun (Lond) 39: 79, 2019.

106. Tran E, Robbins PF and Rosenberg SA: 'Final common pathway' of human cancer immunotherapy: Targeting random somatic mutations. Nat Immunol 18: 255-262, 2017.

107. Butterfield LH: Cancer vaccines. BMJ 350: h988, 2015.

108. Han XJ, Ma XL, Yang L, Wei YQ, Peng Y and Wei XW: Progress in neoantigen targeted cancer immunotherapies. Front Cell Dev Biol 8: 728, 2020.
109. Jiang T, Shi T, Zhang H, Hu J, Song Y, Wei J, Ren S and Zhou C: Tumor neoantigens: From basic research to clinical applications J Hematol Oncol 12: 93, 2019.

110. Sahin U, Derhovanessian E, Miller M, Kloke BP, Simon P, Löwer M, Bukur V, Tadmor AD, Luxemburger U, Schrörs B, et al: Personalized RNA mutanome vaccines mobilize poly-specific therapeutic immunity against cancer. Nature 547: 222-226, 2017.

111. Ott PA, Hu Z, Keskin DB, Shukla SA, Sun J, Bozym DJ, Zhang W, Luoma A, Giobbie-Hurder A, Peter L, et al: An immunogenic personal neoantigen vaccine for patients with melanoma. Nature 547: 217-221, 2017.

112. Iinuma H, Fukushima R, Inaba T, Tamura J, Inoue T, Ogawa E, Horikawa M, Ikeda Y, Matsutani N, Takeda K, et al: Phase I clinical study of multiple epitope peptide vaccine combined with chemoradiation therapy in esophageal cancer patients. J Transl Med 12: 84, 2014.

113. Kono K, Iinuma H, Akutsu Y, Tanaka H, Hayashi N, Uchikado Y, Noguchi T, Fujii H, Okinaka K, Fukushima R, et al: Multicenter, phase II clinical trial of cancer vaccination for advanced esophageal cancer with three peptides derived from novel cancer-testis antigens. J Transl Med 10: 141, 2012.

114. Yasuda T, Nishiki K, Yoshida K, Shiraishi O, Iwama M, Kato H, Yasuda A, Shinkai M, Chiba Y, Okuno K and Nakamura Y: Cancer peptide vaccine to suppress postoperative recurrence in esophageal SCC patients with induction of antigen-specific $\mathrm{CD}^{+}$T cell. J Clin Oncol 35 (Suppl 15): e14635, 2017.

115. Murahashi M, Hijikata Y, Yamada K, Tanaka Y, Kishimoto J, Inoue H, Marumoto T, Takahashi A, Okazaki T, Takeda K, et al: Phase I clinical trial of a five-peptide cancer vaccine combined with cyclophosphamide in advanced solid tumors. Clin Immunol 166-167: 48-58, 2016.

116. Harao M, Hirata S, Irie A, Senju S, Nakatsura T, Komori H, Ikuta Y, Yokomine K, Imai K, Inoue M, et al: HLA-A2-restricted CTL epitopes of a novel lung cancer-associated cancer testis antigen, cell division cycle associated 1 , can induce tumorreactive CTL. Int J Cancer 123: 2616-2625, 2008

117. Obara W, Eto M, Mimata H, Kohri K, Mitsuhata N, Miura I, Shuin T, Miki T, Koie T, Fujimoto H, et al: A phase I/II study of cancer peptide vaccine S-288310 in patients with advanced urothelial carcinoma of the bladder. Ann Oncol 28: 798-803, 2017.

118. Yoshitake Y, Fukuma D, Yuno A, Hirayama M, Nakayama H, Tanaka T, Nagata M, Takamune Y, Kawahara K, Nakagawa Y, et al: Phase II clinical trial of multiple peptide vaccination for advanced head and neck cancer patients revealed induction of immune responses and improved OS. Clin Cancer Res 21: 312-321, 2015

119. Ungerechts G, Engeland CE, Buchholz CJ, Eberle J, Fechner H, Geletneky K, Holm PS, Kreppel F, Kühnel F, Lang KS, et al: Virotherapy research in Germany: From engineering to translation. Hum Gene Ther 28: 800-819, 2017.

120. Moehler M, Goepfert K, Heinrich B, Breitbach CJ, Delic M, Galle PR and Rommelaere J: Oncolytic virotherapy as emerging immunotherapeutic modality: Potential of parvovirus h-1. Front Oncol 4: 92, 2014

121. Conry RM, Westbrook B, McKee S and Norwood TG: Talimogene laherparepvec: First in class oncolytic virotherapy. Hum Vaccin Immunother 14: 839-846, 2018.

122. Tanabe S, Tazawa H, Kagawa S, Noma K, Takehara K, Koujima T, Kashima H, Kato T, Kuroda S, Kikuchi S, et al: Phase I/II trial of endoscopic intratumoral administration of OBP-301, a novel telomerase-specific oncolytic virus, with radiation in elderly esophageal cancer patients. Cancer Res 75: Abstract CT123, 2015.

123. Nemunaitis J, Tong AW, Nemunaitis M, Senzer N, Phadke AP, Bedell C, Adams N, Zhang YA, Maples PB, Chen S, et al: A phase I study of telomerase-specific replication competent oncolytic adenovirus (telomelysin) for various solid tumors. Mol Ther 18: 429-434, 2010.

124. Sharabi AB, Lim M, DeWeese TL and Drake CG: Radiation and checkpoint blockade immunotherapy: Radiosensitisation and potential mechanisms of synergy. Lancet Oncol 16: e498-e509, 2015.

125. Humphries MP, Craig SG, Kacprzyk R, Fisher NC, Bingham V, McQuaid S, Murray GI, McManus D, Turkington RC, James J and Salto-Tellez M: The adaptive immune and immune checkpoint landscape of neoadjuvant treated esophageal adenocarcinoma using digital pathology quantitation. BMC Cancer 20: 500, 2020. 